\title{
Use of magnets for reversible restoration in sculpture. The case of the "Virgen de los Desamparados" in Valencia (Spain)
}

\author{
M. Azahara Rodríguez ${ }^{1}$, Sandra Ruiz-Gómez ${ }^{2}$, Lucas Pérez ${ }^{2,3}$ and Xavier Mas-Barberà 1, ${ }^{*}$
}

Instituto de Restauración del Patrimonio, Universitat Politècnica de València, Camino de Vera s/n 46022, Valencia. Spain.

${ }^{2}$ Depto. Física de Materiales. Universidad Complutense de Madrid. 28040 Madrid, Spain.

${ }^{3}$ Instituto de Magnetismo Aplicado, UCM-CSIC-ADIF, Madrid. Spain.

"corresponding author: jamasbar@upvnet.upv.es

\section{Abstract}

In this paper, we present the use of a magnetic system for restoring a real piece of art: the Virgen de los Desamparados sculpture (1954) by the Valencian sculptor Silvestre d'Edeta (Valencia, Spain). This sculpture is made of artificial stone reinforced with iron rods in the matrix and, before the intervention, showed a high degree of degradation due to various physical, chemical and biological processes causing internal strain, cracks and fragmentation. Several non-destructive imaging techniques (photography, photogrammetry, digital radiography and $3 \mathrm{D}$ virtual reconstruction) have been used to study the original status of the artwork. The materials to produce the prosthesis to restore the sculpture, and the procedure to attach them with magnets and various adhesives, have been addressed in this study. Different theoretical models and simulations have been developed to help the restorer to select the most appropriate magnets and their optimal position. The restoration returns legibility to the piece by restoring the missing head-hair-crown section.

Keywords Prosthesis, adhesion, sculpture, theoretical model, magnetic system.

\section{Introduction}

Current methods of restoring sculptures and ornaments involve using synthetic adhesives, sometimes reinforced by rods of various materials, to assist the joining of different pieces [1-3]. These rods can be made of fiberglass [4] or stainless steel [5], amongst other materials [6-7]. This kind of intervention provides robustness and stability to the artwork, but goes against the principle of minimal intervention and reversibility, as inserting rods is usually a fairly invasive procedure. Therefore, less invasive new technologies and strategies that provide the artwork with similar robustness, while maintaining the reversibility of the restoration, are necessary. The use of magnetic materials is one potential alternative solution to this problem.

Among magnetic materials, permanent magnets - henceforth referred to as magnets are essential components in many technological fields, because of their ability to provide 
a large magnetic response without the application of an external magnetic field. Specifically, a large force appears between two magnets or between a magnet and a ferromagnetic material providing that the temperature is below the Curie temperature, a characteristic temperature above which the magnetic properties of a magnet disappear [8]. NdFeB magnets are an excellent choice for technological applications because they combine a large magnetic response - saturation magnetization above $1.5 \mathrm{~T}$ - with high stability in the presence of external magnetic fields - coercivity above $7 \mathrm{~T}-$ and a relatively low cost. There are two main drawbacks to these magnets: their relatively low Curie temperature $\left(312^{\circ} \mathrm{C}\right)$ that prevents their use in high-temperature applications, and their low corrosion resistance [9]. To avoid corrosion, all commercial NdFeB magnets have protective magnetic coatings.

The use of magnetic materials in the conservation and restoration of cultural heritage is quite recent. Since the late 1980s, magnets have been used in preventative conservation and musealisation, improving the display methods for graphic documents, scrolls, textiles and mural painting [10]. More recently, restorers have used magnetic systems as a tool to produce adhesion between layers of painting, to remove deformations [11], to look for metallic parts in archaeological items, or as a cleaning tool [12]. However, there are only a few examples in which magnetic materials, mainly permanent magnets, are used as an alternative tool for joining fragments or to help in the insertion of reconstructive prostheses in sculptures [13-14]. The use of magnets in the conservation and restoration of sculptures has the potential to fulfil the criteria of minimum intervention, respect for the original artwork, improvement of the aesthetics of the artwork and, most importantly, reversibility. In general, the use of magnets is limited by the skills and criteria of the conservator/restorer, and their application is controversial. Systematic use of magnetic systems in the field of sculpture and ornamental restoration is still not widespread.

In previous works, we showed the possibility of using permanent magnets for the restoration of stone sculptures, developing a systematic method to determine the optimal choice of magnets and the locations to place them in the pieces to be joined, while minimising the impact and ensuring reversibility [15-16]. In these previous works, we used laboratory test samples and artwork created specifically to test the feasibility of the developed method. In this work, we show the potential of this approach by using it to restore a real piece of art: the Virgen de los Desamparados (Virgin of Helpless) sculpture in Valencia, Spain.

\section{Research aim}

This study has been applied to a real case, the Virgen de los Desamparados sculpture (1954), by the well-known Valencian sculptor Manuel Silvestre Montesinos, known as Silvestre d'Edeta [17]. This piece, of great artistic and historical value, reflects the religiosity of La Pobla Llarga, a town close to Valencia. It represents the image of the Virgin on a cloud. Its approximate dimensions are $75 \times 47 \times 23 \mathrm{~cm}^{3}$ (height, width, depth) and it was located in a square named after the Virgin. The sculpture is made of artificial stone, as a result of the hardening of an inorganic mortar (cement binder and calcareous sand), reinforced with iron rods in the matrix. 
Before the intervention, the sculpture showed a high degree of degradation originating from various physical, chemical and biological causes. In particular, the stony surface substrate was lost as a result of water. Flowing water caused oxidation of metallic elements, produced internal strains, and led to the formation of cracks, which finally resulted in the loss of several fragments from the head and the crown (see Figure 1). Although originally located outdoors, after the restoration the piece was moved to the Historical-Art Museum of La Pobla Llarga in Valencia to prevent further degradation.

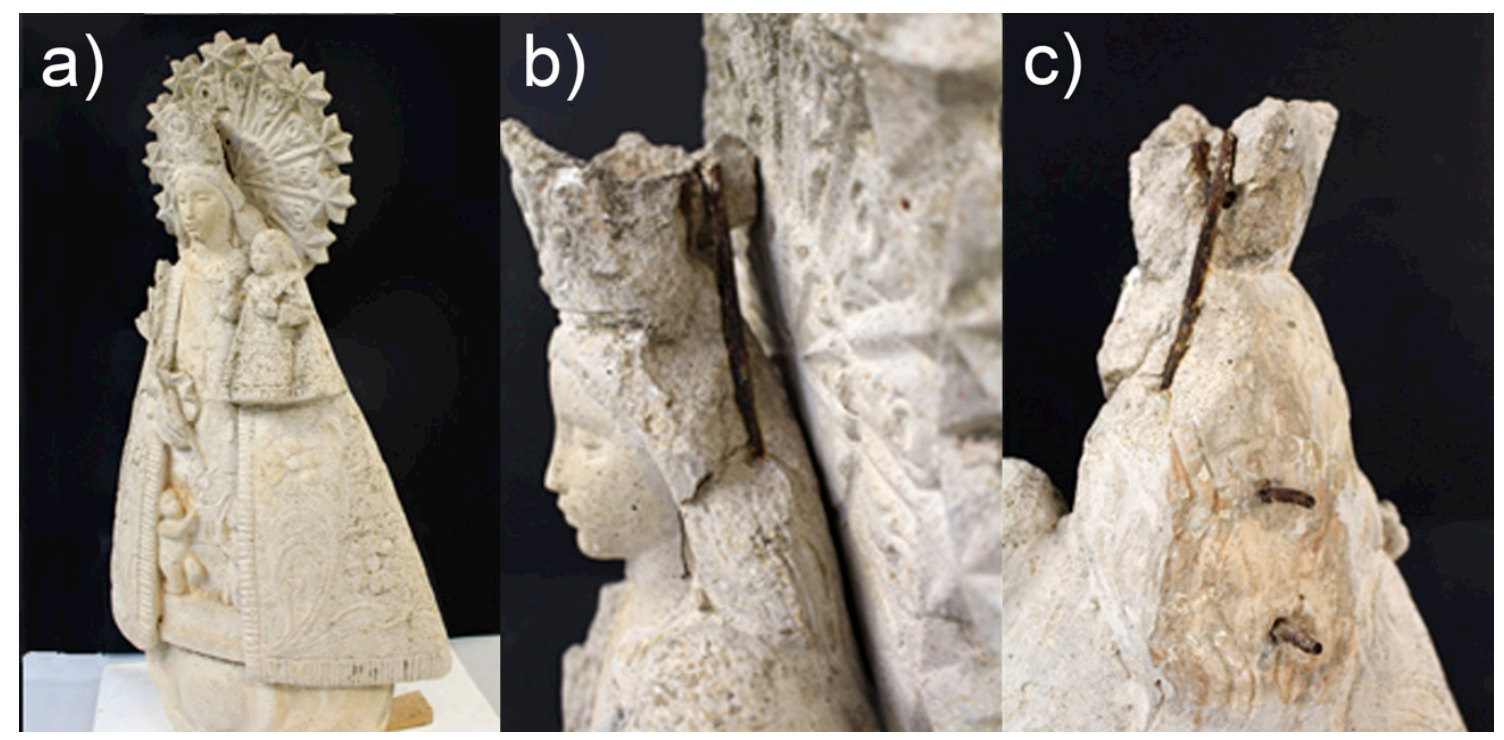

Figure 1 (a-c). The Virgen de los Desamparados sculpture (1954), sculptor Silvestre d'Edeta (Valencia, Spain). a) General view in which the missing sections in the headhair-crown can be seen, leading to reduced aesthetic value. b) Detail of the high degree of degradation originating from different physical, chemical and biological processes, producing internal strain, cracks and loss of fragments; c) Rusty iron rods in the matrix and loss of fragments.

\section{Materials and methods}

Several non-destructive imaging techniques have been used to study the original sculpture: digital photography, radiography and photogrammetry. 3D software for virtual reconstruction of the missing elements of the sculpture was also employed. These techniques were used to document the previous state of the sculpture and to record the interventions and the final results. More specifically, the x-ray imaging allowed the determination of the size and position of existing internal reinforcement, which can be seen in the fractured area of the head-hair-crown (Figure 1). Photogrammetry and 3D reconstruction have been used to calculate the size, shape and volume of the prosthesis.

The materials used for both the test samples and the piece to restore the sculpture, were selected after carefully analysing the artwork. A mortar composed of an inorganic binder (Ledan $\left.C 30^{\circledR}\right)$, carbonate-based sand and gravel $(0.5-2 \mathrm{~mm}$ ), additives (inorganic pigments of different colours) and water were selected. We employed NdFeB magnets with a $\mathrm{Ni} / \mathrm{Cu} / \mathrm{Ni}$ coating supplied by Supermagnete, with magnetization in the axial direction. Three different adhesives were tested to fix the magnets to the prosthesis and to the sculpture: two acrylic (Paraloid $B 72^{\circledR}$ and Plextol B500 ${ }^{\circledR}$ ) and one epoxy (Araldit Standard $\left.^{\circledR}\right)$. Paraloid B-72 (50\% w/v in acetone) and Plextol B500, acrylic resins from 
Rohm and Haas, are well-known and have been studied for conservation of historical pieces [18-20]. Araldite Standard is a strong epoxy resin, a two-part general purpose adhesive (from Araldite).

The force between magnets as well as the adhesive forces produced by the different adhesives was tested in tensile experiments using an Adamel Lhomargy DY30 system. The surface analysis of the magnets was carried out in a JEOL JSM scanning electron microscope equipped with an energy dispersive spectroscopic (EDS) system that allows local composition to be measured.

As mentioned previously, it was important to ensure sufficiently low magnetic fields extending out of the restored pieces to avoid contamination by magnetic particles, contamination that can result in unsatisfactory aesthetics. Finite element calculations were used to calculate the position of the magnets that minimise the external field using the Comsol Multiphysics software. This software uses the fundamental equations of electromagnetism to calculate the external magnetic field produced by a magnetic configuration. We used the magnetic characteristics of $\mathrm{NdFeB}$ magnets as input parameters, extracted from reference [9]. Stones are diamagnetic materials and, for the simulation, we considered the relative magnetic permeability of stone to be equal to 1 .

\section{Theory and calculations}

A theoretical model supported by simulations has previously been developed to help restorers select the most appropriate magnets and their optimal position to ensure joint integrity, while guaranteeing the smallest magnetic field extending out of the sculpture and, thus, avoiding contamination from ambient particles.

The position of the magnets, as well as their magnetic characteristics, were calculated using an analytical model based on the Laws of Statics. The physical basis of the model is simple: the magnetic forces exerted by the magnets in the joint needed to be large enough to ensure that the joined fragment does not move. The model allows the minimum value of the total magnetic force to be calculated by solving two equations. On one hand, all forces - weight, friction, reaction from surfaces, magnetic forces, etc should sum to zero, thus preventing the breaking of the joint through sliding. In addition, the sum of the momenta of the forces should also be zero to prevent the joint from breaking through rotation of the fragment. The different parameters needed in the model - force of the magnets and friction coefficients - have previously been measured using laboratory test samples made with materials similar to that of the sculpture under study [13-14]. Once the total force has been calculated, the number and position of magnets can be determined with the help of finite element simulations to minimise the magnetic field extending out of the artwork. The application of the model to the case under study is detailed below.

Figure 2.a shows schematics of the piece to be restored. Once the magnets were in place, four different forces had to be taken into account: the weight $(W)$, the friction $(F)$, the reaction between the pieces $(R)$ and the magnetic force $(M)$. These three forces needed to cancel to zero to fix the piece in the required position.

$$
\vec{W}+\vec{F}+\vec{R}+\vec{M}=0 \text { (eq. } 1 \text { ) }
$$

Considering the horizontal direction, $\mathrm{M}=\mathrm{R}$. 
Considering the vertical direction:

$$
\left.\begin{array}{c}
W=F \\
F=\mu R=\mu M
\end{array}\right\} \Rightarrow M=\frac{W}{\mu} \text { (eq. 2) }
$$

According to equation 2, the selection of magnets depends only on the weight and the friction coefficient between the different pieces. However, in order to ensure equilibrium, the rotation of the restored piece should also be avoided, i.e., it is also important to ensure equilibrium of momenta.

$$
M d_{1}=W d_{2} \cos \alpha \Rightarrow M=\frac{W d_{2} \cos \alpha}{d_{1}}(\text { eq. 3) }
$$

Equation 3 provides a new value for the magnetic force needed to ensure equilibrium. If we denote $M_{f}$ as the value obtained from the force equilibrium equation (eq. 2) and $M_{m}$ as the value obtained from the momenta equilibrium equation (eq. 3 ), the largest value should be used to select the magnets.
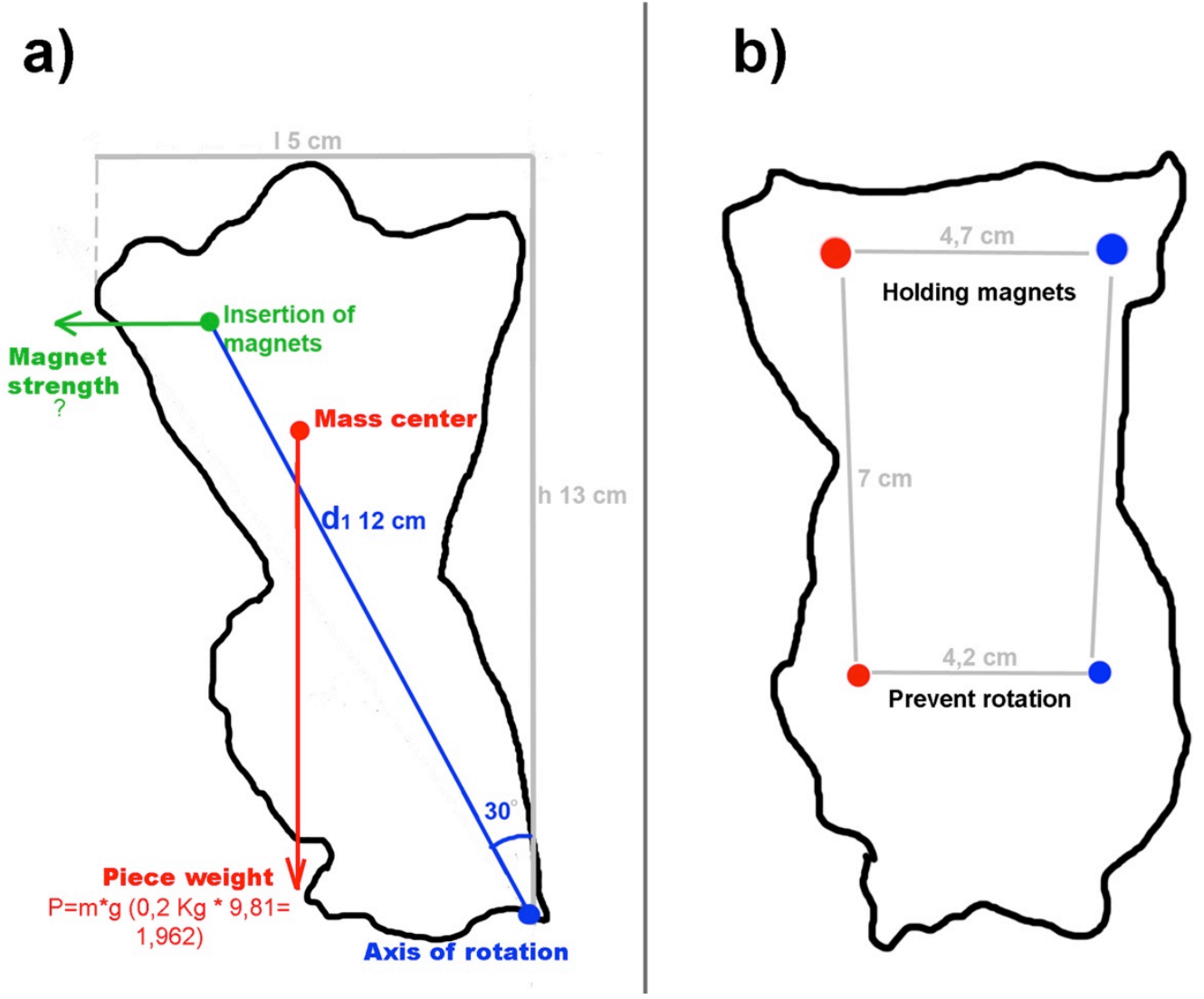

Figure $2(a-b)$. Theoretical model applied to the prosthesis. a) Simulation to select the best magnets and their optimal position. b) In this case, the centre of mass is really close to the axis of rotation, which makes rotation difficult.

\section{Results and discussion}

Before starting the restoration procedure, it was important to select the appropriate magnets and adhesives to use in the joint. The weight of the prosthesis was estimated 
using photogrammetry, to be approximately $200 \mathrm{~g}$. Using equation 2 and considering $\mu=0.57-$ the value measured in similar stony materials - we obtain $M_{f}=3.44 \mathrm{~N}$. Using equation 3 and considering the dimensions of the prosthesis (see Figure 2.a), a value of $M_{m}=0.41 \mathrm{~N}$ was obtained. This difference is mainly due to the shape of the prosthesis: the centre of mass is close to the axis of rotation, which impedes rotation. Therefore, the magnetic force required to ensure equilibrium is $3.44 \mathrm{~N}$. In order to include a safety factor, this force was doubled, so two model S-04.1.5N magnets from Supermagnete were selected, each of which provide a force of $3.5 \mathrm{~N}$ according to manufacturer specifications. The two magnets were placed in opposite magnetic configurations in order to reduce the magnetic field extending out of the prosthesis by closing the magnetic flux (see Figure 2.b). In addition, two smaller magnets were added (model S-02-01-N) to increase stability.

Since, after restoration, the piece was to be displayed indoors, there was no requirement for external temperature or corrosion to be taken into account. However, preliminary tests of the resistance of the magnets to ambient conditions were carried out by placing a pair of magnets outdoors in the city of Valencia for 3,000 hours with no protection, with a mean temperature of $27^{\circ} \mathrm{C}$ and mean humidity of $88 \%$. After this period, the magnetic force between magnets was reduced by only $5 \%$, probably due to handling. Compositional analysis of the surface did not reveal the presence of $\mathrm{Nd}$, which indicated that the coating was already covering and protecting the magnet. Further research is planned on this topic and will be reported elsewhere, but these preliminary tests allow confidence in the use of this system in outdoor sculptures.

The magnets were fixed to the prosthesis and the artwork using an adhesive. Therefore, the adhesive force was also required to be larger that $\mathrm{M}_{\mathrm{f}}$. Three different adhesives were tested in a traction experiment: two acrylic (Paraloid B72 and Plextol B500) and one epoxy (Araldit Standard ${ }^{\circledR}$ ). For the tests, $2 \times 2 \times 2 \mathrm{~cm}^{3}$ cubes of stone were glued using the different adhesives. The measured adhesion forces and the elongation before separation for the different adhesives are listed in table 1.

Table 1. Different adhesives studied and their adhesion forces $(\mathrm{N})$ and elongation $(\mathrm{mm})$.

\begin{tabular}{|c|c|c|c|}
\hline & Paraloid B72 & Plextol B500 & Araldit Standard \\
\hline Force (N) & 72 & 84 & 241 \\
\hline Elongation (mm) & 0.38 & 0.81 & - \\
\hline
\end{tabular}

The adhesion force for the Araldit Standard is too large, which could lead to reversibility problems. Both Paraloid B72 and Plextol B500 show similar adhesive force, large enough to support the prosthesis. In addition, acrylic adhesives are reversible with solvents whereas Araldit is not. Therefore the acrylic adhesives are better suited to reversible restorations, particularly in pieces to be kept indoors such as the sculpture under consideration. Considering that the elongation measured in the Plextol B500 is too large for a structural joint, it was decided to use Paraloid B72. 
The magnetic field generated by the magnets placed in the selected positions was calculated using Comsol software. Figure 3 shows the magnetic field calculated in different planes parallel to the fracture. The magnetic field close to the magnets was measured to be 10 times larger than the magnetic field of the Earth $(25 \mu \mathrm{T})$. However, at a distance of $5 \mathrm{~cm}$, already inside the prosthesis the magnetic field is weaker than that of the Earth. Therefore, the presence of the magnets inside the artwork will not produce contamination due to atmospheric ferromagnetic particles.
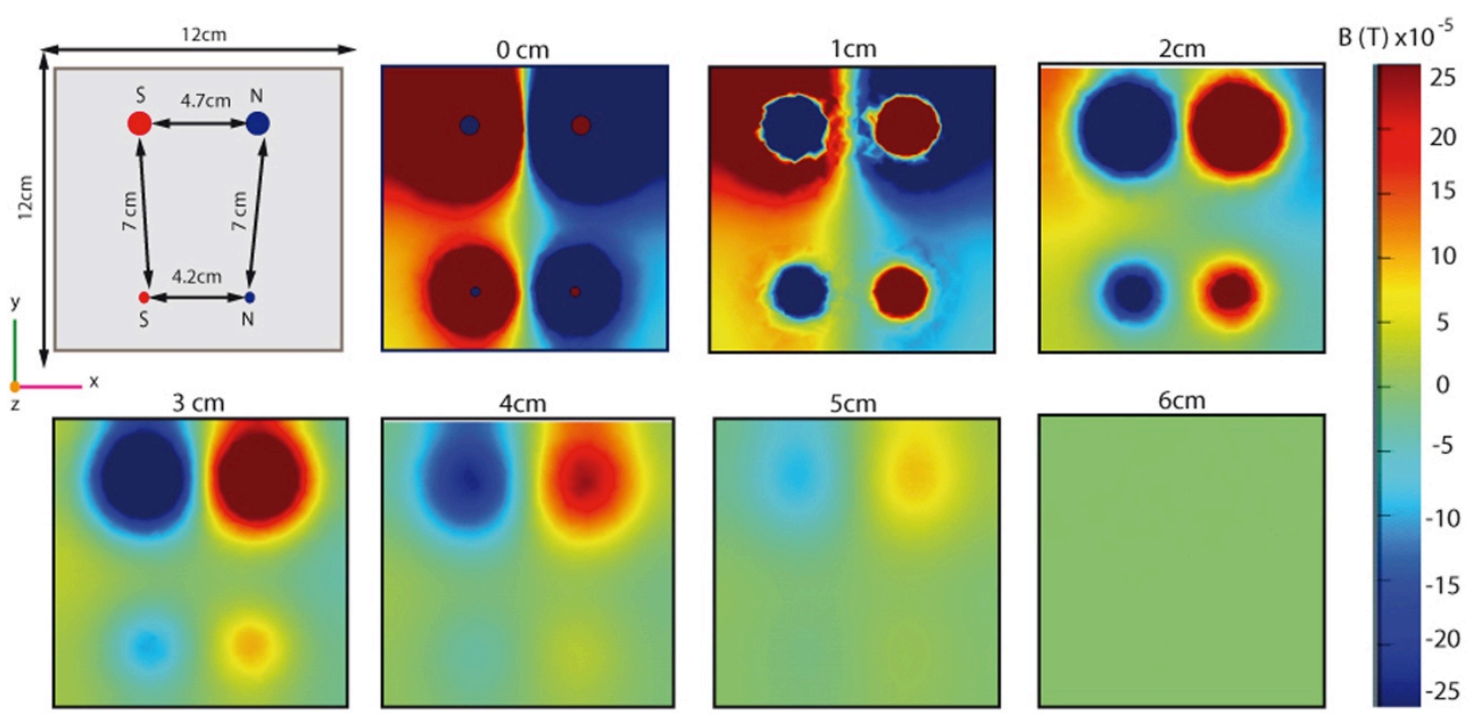

Figure 3. Simulation of the magnetic field using the Comsol Multiphysics software. The sequence shows that the magnetic field is practically zero at a distance of $6 \mathrm{~cm}$ from the magnets.

All these calculations were applied to the restoration of the Virgen de los Desamparados. First, the magnets were fixed to the original fragment with Paraloid B72 in the previously calculated positions. The original fragment was then protected with plastic film and the prosthesis was produced in-situ. The prosthesis and the plastic film were then removed, the magnets were attached to the prosthesis and the two parts were joined magnetically to incorporate the missing head-hair-crown section into the sculpture, thereby returning legibility to the sculpture (see Figure 4).

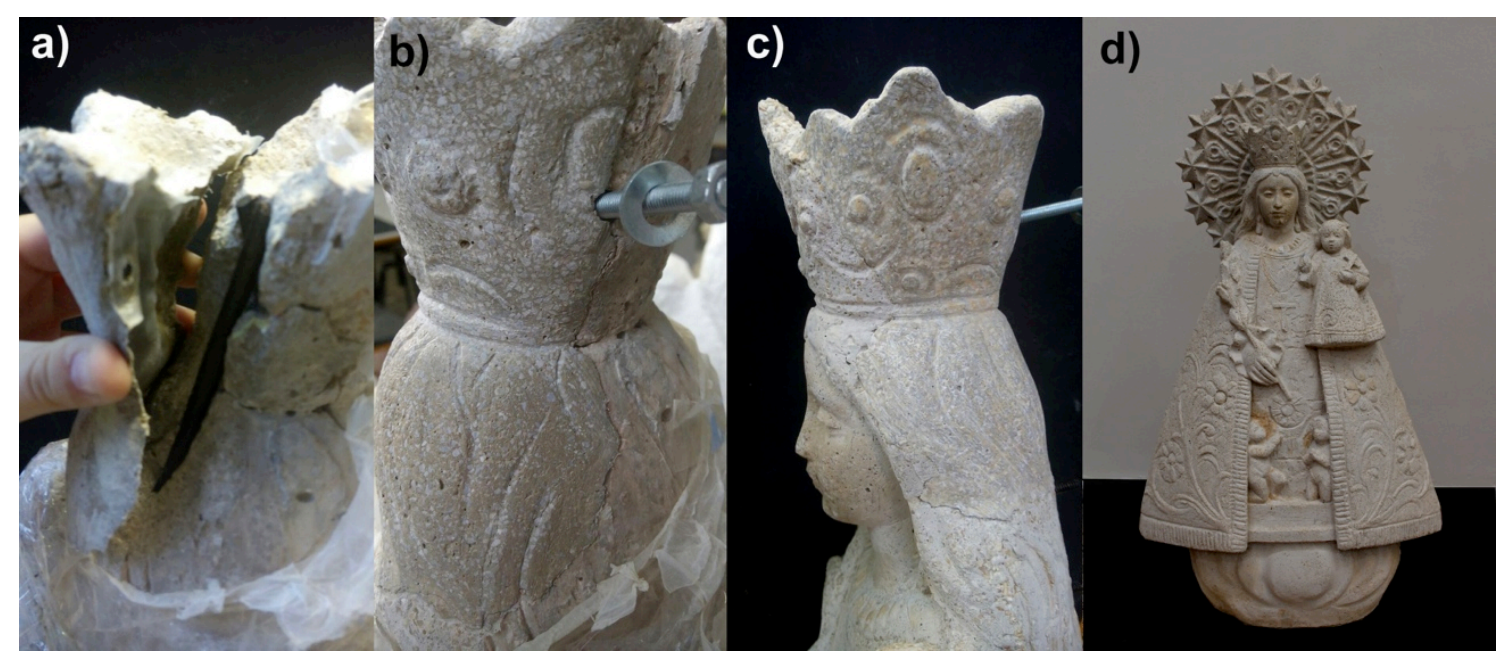


Figure 4 (a-d). Restoration of the Virgen de los Desamparados. a) Internal detail of the prosthesis applied. The magnets inside the inorganic mortar can be seen; b) External view of the prosthesis before the chromatic intervention; $c$ ) after the colour reintegration; d) General view of the restored sculpture.

\section{Conclusions}

This study of the application of magnetic systems to a real sculpture shows the need to develop appropriate and systematic magnetic systems in the field of sculptural and ornamental works. There are only a few examples in which magnetic materials have been applied, but their use has been limited by the skills and criteria of the conservator/restorer, since they did not perform previous studies. In contrast, the theoretical model and simulation developed in this work will help the restorer to select the most appropriate magnets and to calculate their optimal position. This approach guarantees the smallest magnetic field extending out of the sculpture, and avoids contamination from ambient particles. Paraloid B72 was selected to fix the magnets to the prosthesis, and the artwork showed good adhesive force, enough elongation and reversibility of the intervention. The restoration process has returned legibility to the Virgen de los Desamparados by restoring the missing head-hair-crown section.

\section{References}

[1] Ivorra, S., García-Barba, J., Mateo, M., Pérez-Carramiñana, C. and Maciá, A., 2013, Partial collapse of a ventilated stone façade: Diagnosis and analysis of the anchorage system in Engineering Failure Analysis 31, 290-301.

http://dx.doi.org/10.1016/j.engfailanal.2013.01.045

[2] Contrafatto, L. and Cosenza, R., 2014, Behaviour of post-installed adhesive anchors in natural Stone in Construction and Building Materials 68, 355-369.

https://doi.org/10.1016/j.conbuildmat.2014.05.099

[3] Raftery, G.M. and Whenlan, C., 2014, Low-grade glued laminated timber beams reinforced using improved arrangements of bonded-in GFRP rods in Construction and Building Materials 52, 209-220.

https://doi.org/10.1016/j.conbuildmat.2013.11.044

[4] Polacek, P., Jancar, J., 2008, Effect of filler content on the adhesion strength between UD fiber reinforced and particulate filled composites in Composites Science and Technology 68, 251-259.

https://doi.org/10.1016/i.compscitech.2007.03.043

[5] Rosewitz, J., Muir, C., Riccardelli, C., Rahbar, N. and Wheeler, G., 2016, A multimodal study of pinning selection for restoration of a historic statue in the Materials and Design 98, 294-304.

https://doi.org/10.1016/j.matdes.2016.03.004 
[6] Mas-Barberà, X., (2011), Conservación y restauración de materiales pétreos: diagnóstico y tratamientos. Valencia, UPV. ISBN 978-8483635834, 190 pp.

[7] Quagliarini, E., Monni, F., Bondioli, F. and Lenci, S., 2016, Basalt fiber ropes and rods: Durability tests for their use in building engineering in the Journal of Building Engineering 5, 142-150.

\section{https://doi.org/10.1016/j.jobe.2015.12.003}

[8] Coey, J.M.D, (1996), Rare-earth Iron Permanent Magnets. Oxford University Press. ISBN-10: 0198517920. ISBN-13: 9780198517924.542 pp.

[9] Sugimoto, S., 2011, Current status and recent topics of rare-earth permanent magnets. J. Phys D. Appl. Phys. 44. 064001.

[10] Derbyshire, Alan. (2005): «The new miniatures gallery» [on line], V\&A Conservation Journal Autumn, $\mathrm{n}^{\circ} \quad 51, \quad \mathrm{pp}$. 2-4. Available in: $<$ http://www.vam.ac.uk/content/journals/conservation-journal/issue-51/the-newminiatures-gallery/>. [Consulted: 2/20/2017].

[11] Bestetti, R., 2005, Risarcimento strutturale trattamento delle lacune il caso del dipinto giardini romani di Giacomo Balla of the ICC Congreso Nazionale IGIIC lo stato dell'arte, Palermo, 336-343.

http://www.academia.edu/17195916/Restauro strutturale e trattamento delle lacune il caso del dipinto Giardini Romani di Giacomo Balla Open Access.

[12] Bonini, Massimo et al. (2007): «Nanomagnetic sponges for the cleaning of works of art» [on line], Langmuir n. ${ }^{\circ}$ 23, pp. 8681-8685. Available in: <http://pubs.acs.org/doi/pdf/10.1021/ la701292d>. [Consulted: 2/20/2017].

[13] Lonrenzi, P.F. and Sorella, F. 2014, II San Giovannino di Úbeda restituito, El San Juanito de Úbeda restituido of the II San Giovannino di Úbeda restituito-El San Juanito de Úbeda restituido (Problemi di conservazione e restauro), Elena Mariotti (eds. Edifir edizioni Firenze), Pisa, 116-117.

[14] Watson Adsit, K., 2011, An Attractive Alternative: The Use of Magnets to Conserve Homer by John Chamberlain in WAAC Newsletter. Volume 33. № 2, 16-21.

http://cool.conservation-us.org/waac/wn/wn33/wn33-2/wn33-204.pdf Open access

[15] Rodríguez, M.A., Mas-Barberà. X. and Pérez, L., 2014, Estudio para optimizar las uniones de fragmentos en escultura y ornamentos mediante sistemas magnéticos of the Jornadas Emerge 2014: Jornadas de Investigación Emergente en Conservación y Restauración de Patrimonio, M. V. Vivancos, M. T. Domenech, M. Sánchez and M. J. Osca (eds.), Valencia, UPV and IRP, 471-477.

https://riunet.upv.es/handle/10251/47276 Open Access.

[16] Rodríguez, M.A., Mas-Barberà. X., Pérez, L. and Ruiz-Gómez, S., 2015, Estudio de sistemas magnéticos a base de imanes para uniones de fragmentos y prótesis a la obra original escultórica of the La Ciencia y el Arte V. Ciencias y tecnologías aplicadas a la 
conservación del patrimonio, consejo editorial IPCE (eds.), Madrid, IPCE and Museo Centro de Arte Reina Sofía, 121-135.

https://sede.educacion.gob.es/publiventa/la-ciencia-y-el-arte-v-cienciasexperimentales-y-conservacion-del-patrimonio/conservacion-restauracion/20407C Open Access.

[17] Prats Rivelles, R., 1984, Silvestre de Edeta, oficio de sobriedad. Valencia: Vicente García, ISBN 8485094387, 96 pp.

[18] Horie , C.V. (1997). Materials for Conservation. Oxford, Butterworth-Heinemann. 1997.

[19] Yang, L., Wang, L., Wang, P., 2007. Investigation of photo-stability of acrylic polymer Paraloid B72 used for conservation. Sci. Conserv. Archaeol. 19, 54e58

[20] Vaz, M.F., Pires, J., Carvalho,A.P., 2008. Effect of the impregnation treatment with Paraloid B-72 on the properties of old Portuguese ceramic tiles. J. Cult. Herit. 9, $269 \mathrm{e} 276$.

https://doi.org/10.1016/j.culher.2008.01.003 